\title{
Single Alien Chromosome Additions from Shallot (Allium cepa L. Aggregatum group) Increase Endogenous Polyphenol Contents in Japanese Bunching Onion
}

\author{
Shigenori Yaguchi, Naoki Yamauchi and Masayoshi Shigyo* \\ Department of Biological and Environmental Science, Faculty of Agriculture, Yamaguchi University, 1677-1 Yoshida, Yamaguchi \\ 753-8515, Japan
}

Eight members of the Allium fistulosum L. - shallot (Allium cepa $\mathbf{L}$. Aggregatum group) monosomic addition line $(2 n=17, F F+1 A-F F+8 A)$ proved to be very effective in revealing the effects of single alien chromosomes from $A$. cepa on the production of polyphenol in the green leaf tissues of $A$. fistulosum. The determination of polyphenol content in the green leaf tissue of these monosomic additions was carried out monthly from January 2002 to December 2003. Throughout the 2-year period, every monosomic addition accumulated polyphenols in green leaf tissues. Two-way ANOVA revealed significant differences, at the $1 \%$ level, in the polyphenol contents of the various monosomic addition types as well as in various months. Dunnett's test showed that four monosomic additions $(\mathrm{FF}+2 \mathrm{~A}, \mathrm{FF}+5 \mathrm{~A}, \mathrm{FF}+6 \mathrm{~A}$, and $\mathrm{FF}+8 \mathrm{~A})$ caused a greater increase in the amount of polyphenol content than did A. fistulosum. The levels of polyphenol accumulation in the remaining four monosomic additions and A. fistulosum were almost the same. A phenylalanine ammonialyase gene of shallot was allocated to chromosome $2 \mathrm{~A}$ using two sets of the monosomic additions. These results indicate that the genes related to polyphenol production may be located on the $2 \mathrm{~A}, 5 \mathrm{~A}, 6 \mathrm{~A}$, and $8 \mathrm{~A}$ chromosomes of shallot.

Key Words: alien monosomic addition line, Allium fistulosum L., leaf vegetable, phenylalanine ammonialyase, polyphenol.

\section{Introduction}

Polyphenols are secondary plant metabolites and bioactive molecules ubiquitously distributed in all plants. Polyphenols influence the morphology, growth, and reproduction of plants, as well as their resistance to parasites and environmental stresses (Bravo, 1998). The most common and important low-molecular-weight phenolic compounds are simple phenolic derivatives and flavonoids. The presence of polyphenols in plants is influenced by genetic factors and environmental conditions (Tomas-Barberan and Espin, 2001).

Recent interest in food polyphenols has increased owing to their roles as antioxidants and scavengers of free radicals. Onions (Allium cepa L.) contain a large number of flavonoids, which are present in the colored scales of the edible part (Bahorun et al., 2004; Chu et al., 2000). Among 11 onion varieties, shallot (A. cepa Aggregatum group) was found to have the highest polyphenol content (Yang et al., 2004). On the other hand, the Japanese bunching onion (A. fistulosum L.) has

Received; September 4, 2008. Accepted; March 12, 2009.

* Corresponding author (E-mail: shigyo@yamaguchi-u.ac.jp). a white leaf sheath and low polyphenol content. A. fistulosum is frequently used raw in salads or as an herb to flavor soups and plays an important role in the Japanese diet; therefore, it is desirable to increase the polyphenol contents of $A$. fistulosum in order to increase the intake of food polyphenols by Japanese people.

A complete set of A.fistulosum-shallot (A. cepa Aggregatum group) monosomic addition lines $(2 n=17$, $\mathrm{FF}+1 \mathrm{~A}-\mathrm{FF}+8 \mathrm{~A}$ ) was established in a previous study (Shigyo et al., 1996). Previous studies also revealed that several lines with alien chromosomes which possessed the key regulatory and structural genes for flavonoid metabolism showed different flavonoid compositions in the leaf sheath tissues (Masuzaki et al., 2006a, 2006b; Shigyo et al., 1997b).

An investigation of the polyphenol substance in the leaf blade (green leaf) tissues of the Allium monosomic additions should reveal changes in the polyphenol contents of A.fistulosum and show the chromosomal locations of the shallot genes, which are important for polyphenol metabolism. In the present study, the polyphenol contents in a complete set of A. fistulosumshallot monosomic additions were evaluated to determine the effect of a single alien chromosome from 
the shallot on polyphenol production in A.fistulosum.

\section{Materials and Methods}

\section{Plant materials}

The plant materials were a complete set of A. fistulosum - shallot monosomic additions $(2 n=2 x+1$ $=17, \mathrm{FF}+1 \mathrm{~A}-\mathrm{FF}+8 \mathrm{~A})$ and a control plant, Japanese bunching onion (A. fistulosum 'Kujyo-hoso', $2 n=2 x=$ 16 , FF). The monosomic additions were grown in an experimental field at Yamaguchi University $\left(34^{\circ} \mathrm{N}\right.$, $131^{\circ} \mathrm{E}$ ) over a 2-year period (January 2002-December 2003). Cultivation and fertilizer applications were carried out according to the procedures of Shigyo et al. (1997a).

\section{Polyphenol extraction and quantitative analyses}

Extraction was performed monthly from January 2002 to December 2003. Two grams of green leaf tissue was extracted by $70 \%$ ethanol according to the method of Hang et al. (2004). After the extract was adequately diluted with water, polyphenol contents were determined as described by Folin and Denis (1915), with minor modifications. One milliliter of $1 \mathrm{~N}$ phenol reagent (Wako Pure Chemical Industries Ltd., Osaka, Japan) was mixed with $1 \mathrm{~mL}$ diluted extract. After $3 \mathrm{~min}, 1 \mathrm{~mL}$ of $10 \%$ sodium carbonate aqueous solution was added to the extract solution, and the mixture was incubated for $60 \mathrm{~min}$ at room temperature. The polyphenol contents were quantified according to absorbance at $530 \mathrm{~nm}$ on a U-2001 spectrophotometer (Hitachi High-Technologies Corporation, Tokyo, Japan). Quantification was achieved by comparison in a catechol calibration curve.

\section{$D N A$ isolation}

Total genomic DNA of two complete sets of A. fistulosum-shallot monosomic additions and control plants was isolated from fresh green leaf tissue using a mini-prep DNA-isolation method (van Heusden et al., 2000).

\section{PCR primer design}

Primer sets to amplify a segment of the gene-encoding enzyme of phenylalanine ammonialyase (PAL) in a possible sulfur assimilation pathway were designed with the GENETYX 6.1.3 software (Genetyx, Tokyo, Japan) based on the GenBank ${ }^{\mathrm{TM}}$ accession number AY541031 (complete cDNA sequence of Allium cepa PAL). Primer sets were as follows: forward; 5'-CTC CTC CAA GGC TAT TCG GGT ATC-3', reverse; 5'-GGG TGG TGC TTT AGC TTG TGG-3'.

\section{PCR amplification and digestion of PCR products}

PCR amplifications were conducted with $50 \mathrm{ng}$ genomic DNA, each of the primers at $1 \mu \mathrm{M}, 0.25 \mathrm{mM}$ dNTPs, a $1 \times$ Ex Taq buffer (Takara Bio Inc., Japan), and 0.5 units Ex Taq polymerase in a volume of $25 \mu \mathrm{L}$. PCR was performed as follows: initial denaturation of
3 min at $94^{\circ} \mathrm{C}, 35$ cycles of PCR amplification $(1 \mathrm{~min}$ denaturation at $94^{\circ} \mathrm{C}, 1 \mathrm{~min}$ annealing at $68^{\circ} \mathrm{C}$, and $1 \mathrm{~min}$ primer extension at $72^{\circ} \mathrm{C}$ ) on a Program Thermal Cycler iCycler $^{\mathrm{TM}}$ (Bio-Rad Laboratories Inc., USA). The ramp times were measured under default conditions that adjusted temperature at the maximum ramp rate with the minimum ramp time. Nine microliters of the PCR products was incubated for $2 \mathrm{~h}$ at $37^{\circ} \mathrm{C}$ in a volume of $15 \mu \mathrm{L}$ using 2 units of a restriction enzyme and was subsequently resolved by electrophoresis on $2 \%$ agarose gels. Restriction digestion with Alu I was used in an attempt to generate polymorphisms.

\section{Statistical analyses}

Monthly polyphenol content data for the eight addition lines and A. fistulosum were used for two-way analysis of variance (ANOVA). Dunnett's test was employed to compare the polyphenol contents of A.fistulosum and each monosomic addition. Statistical analyses were performed using SPSS 11.5 software with advanced models (SPSS Japan Inc., Tokyo, Japan).

\section{Results}

\section{Determination of polyphenol contents in monosomic additions}

As shown in Figure 1, the polyphenol contents in A. fistulosum (control) varied from 41.5 to $74.6 \mathrm{mg} / 100 \mathrm{~g}$ fresh weight (FW) (average, $56.7 \mathrm{mg} / 100 \mathrm{~g} \mathrm{FW}$ ) as catechol equivalents. Seasonal changes in the polyphenol contents of $A$. fistulosum did not vary widely. Polyphenol accumulation in all monosomic addition lines showed a small decrease from May to June with the exception of $\mathrm{FF}+6 \mathrm{~A}$ in 2003. The polyphenol contents in $\mathrm{FF}+6 \mathrm{~A}$ (average, $83.1 \mathrm{mg} / 100 \mathrm{~g} \mathrm{FW}$ ) were higher than in A. fistulosum throughout the 2-year study. FF $+2 \mathrm{~A}, \mathrm{FF}$ $+5 \mathrm{~A}$, and $\mathrm{FF}+8 \mathrm{~A}$ also accumulated high volumes of polyphenol (averages, 73.3, 67.2, and $76.2 \mathrm{mg} / 100 \mathrm{~g} \mathrm{FW}$, respectively). These monosomic addition lines showed that alien chromosomes, such as $2 \mathrm{~A}, 5 \mathrm{~A}, 6 \mathrm{~A}$, and $8 \mathrm{~A}$, caused the polyphenol contents to increase. The polyphenol contents of FF +7A were slightly higher than those of A. fistulosum. Polyphenol accumulation in the remaining three monosomic additions $(\mathrm{FF}+1 \mathrm{~A}, \mathrm{FF}+3 \mathrm{~A}$, and $\mathrm{FF}+4 \mathrm{~A}$ ) showed the same tendency as A. fistulosum. Two-way ANOVA revealed a significant difference at the $1 \%$ level in the monthly contents of the polyphenol substance as well as among plant materials (Table 1). Dunnett's test showed significant differences between the control and the four monosomic additions $(\mathrm{FF}+2 \mathrm{~A}$, $\mathrm{FF}+5 \mathrm{~A}, \mathrm{FF}+6 \mathrm{~A}$, and $\mathrm{FF}+8 \mathrm{~A})$.

\section{Chromosomal assignment of a candidate gene involved} in polyphenol production

The primer set for the PAL gene of $A$. cepa amplified a single band of approximately $1,000 \mathrm{bp}$ in A. fistulosum and shallot. After both PCR products were digested with the enzyme Alu I, a polymorphism between $A$. fistulosum 
and shallot was detected via $2 \%$ agarose gel electrophoresis. In the two complete sets of monosomic additions, the same restriction fragment length polymor-

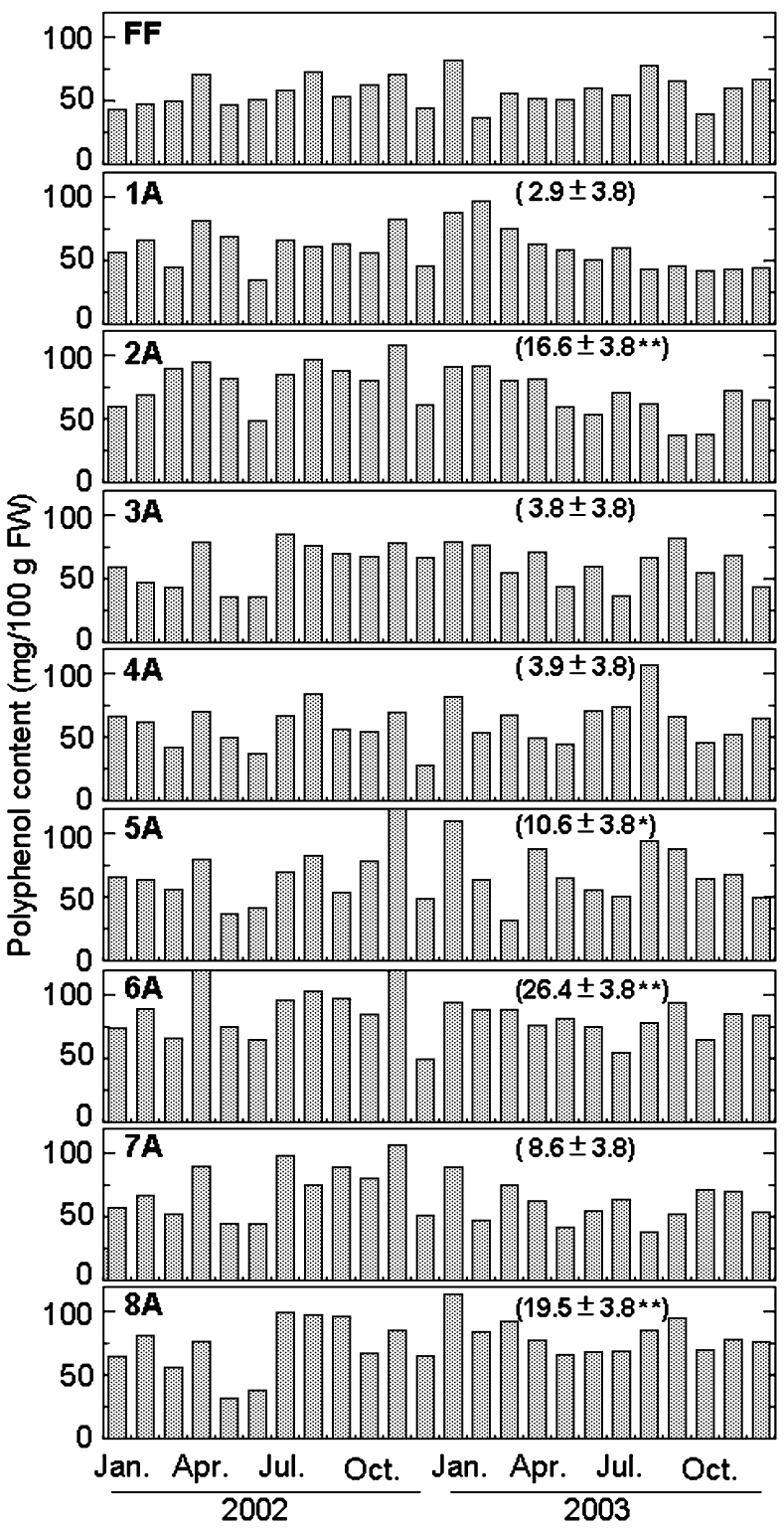

Fig. 1. The year-round variations of polyphenol contents in a complete set of monosomic additions (1A-8A) compared with Allium fistulosum (FF). Values in parentheses show the mean difference $\pm \mathrm{SE}$ of polyphenol content between A. fistulosum and each monosomic addition. Dunnett's multiple comparison test was used for mean separation. *, ** significant at $P \leq 0.05,0.01$, respectively. phism (RFLP) patterns as in shallot were present only in $\mathrm{FF}+2 \mathrm{~A}$ (Fig. 2). This result revealed that the PAL gene of the shallot was located on chromosome $2 \mathrm{~A}$.

\section{Discussion}

Different effects of a single alien chromosome addition were observed in several chemical composition productions in previous studies. The production of Lascorbic acid (vitamin $\mathrm{C}$ ) in three monosomic additions $(\mathrm{FF}+1 \mathrm{~A}, \mathrm{FF}+2 \mathrm{~A}$, and $\mathrm{FF}+8 \mathrm{~A})$ showed a significant increase than in A.fistulosum and the remaining five monosomic additions showed the same tendency as A. fistulosum (Yaguchi et al., 2008a). In the production of non-reducing sugar, including sucrose and fructan, $\mathrm{FF}+8 \mathrm{~A}$ showed significantly higher sucrose accumulation but FF $+2 \mathrm{~A}$ hardly accumulated non-reducing sugar (Hang et al., 2004; Yaguchi et al., 2008b). Almost all monosomic addition lines showed a decrease of the content of $S$-alk(en)yl-L-cystein sulfoxides, which is known as a flavor precursor of Allium crops, compared with A.fistulosum (Yaguchi et al., unpublished data). Four monosomic additions $(\mathrm{FF}+2 \mathrm{~A}, \mathrm{FF}+5 \mathrm{~A}, \mathrm{FF}+6 \mathrm{~A}$, and $\mathrm{FF}+8 \mathrm{~A}$ ) showed an increase of polyphenol contents compared with the control in this study; therefore, it could be expected that the increase of polyphenol contents in A. fistulosum would be accomplished by alien chromosome addition from shallot to A.fistulosum.

In the present study, several monosomic addition lines showed a small decrease of polyphenol content from May to June. Previous studies of the seasonal change of sugar accumulation in the monosomic addition lines revealed that the sugar content in the green leaf tissues of monosomic addition lines decreased from spring to summer and then increased from autumn to winter (Hang et al., 2004; Yaguchi et al., 2008b). Bolting and flowering were observed in all plant materials between March and May during the term of this study. These changes of the growth period in spring would affect the decrease of polyphenol and sugar content in green leaf tissues from several monosomic addition lines and A. fistulosum.

Sakakibara et al. (2003) reported that A. fistulosum polyphenols consisted of kaempferol glycosides (79.1$95.4 \mu \mathrm{mol} / 100 \mathrm{~g} \mathrm{FW})$ and caffeic acids $(8.8-10.0 \mu \mathrm{mol} /$ $100 \mathrm{~g} \mathrm{FW})$. Based on these data, the total polyphenol content was 44.3-52.8 mg/100 g FW. Yang et al. (2004) reported that shallot had the highest polyphenol content $(114.7 \pm 10.0 \mathrm{mg}$ of gallic acid equivalent $/ 100 \mathrm{~g} \mathrm{FW})$ among 11 onion varieties. In the present study, FF $+6 \mathrm{~A}$

Table 1. Analysis of variance for total polyphenol contents in monosomic additions and Allium fistulosum.

\begin{tabular}{lcccr}
\hline \hline Source & Degree of freedom & Sum of squares & Mean square & F value \\
\hline Total & 215 & & & \\
Months & 23 & 33670.60 & 1463.94 & $8.66^{\mathrm{z}}$ \\
Plant materials & 8 & 15161.09 & 1895.14 & $11.22^{\mathrm{z}}$ \\
Error & 184 & 31091.58 & 168.98 & \\
\hline
\end{tabular}

\footnotetext{
${ }^{\mathrm{z}}$ for significance at the $1 \%$ level
} 


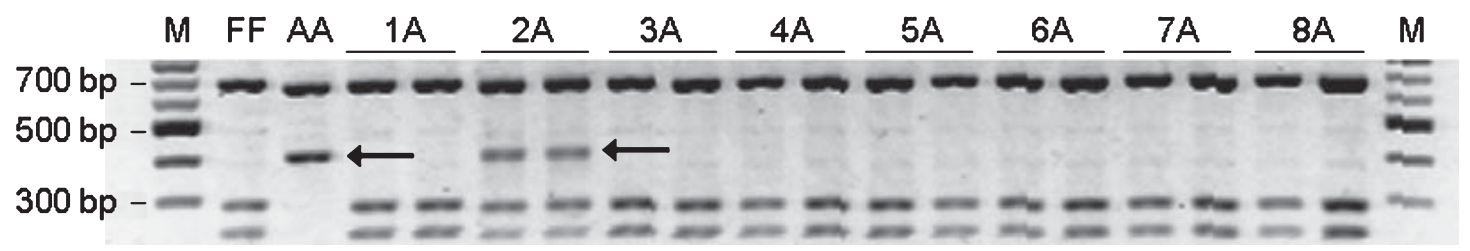

Fig. 2. Electrophoretogram showing the chromosomal location of phenylalanine ammonialyase gene in shallot. FF, Allium fistulosum; AA, shallot; 1A-8A, two complete sets of A. fistulosum - shallot monosomic addition lines. M, molecular size marker (100 bp DNA ladder). Arrows point to the shallot-specific band.

showed a higher accumulation of polyphenol (average, $83.1 \mathrm{mg} / 100 \mathrm{~g} \mathrm{FW}$ ) than A. fistulosum (average, $56.7 \mathrm{mg} /$ $100 \mathrm{~g}$ FW). The respective polyphenol contents of broccoli (Brassica oleracea L.), spinach (Spinacia oleracea L.), and yellow onion, which are considered to have high polyphenol levels, were $80.8,79.6$, and $68.9 \mathrm{mg}$ of gallic acid equivalent $/ 100 \mathrm{~g} \mathrm{FW}$ (Chu et al., 2002). FF $+6 \mathrm{~A}$ contained a substantial amount of polyphenol compounds compared with those vegetables; therefore, $\mathrm{FF}+6 \mathrm{~A}$ could be utilized as a desirable dietary source of polyphenols in fresh vegetables, as in the case of the new A. fistulosum cultivars.

Sakakibara et al. (2003), who developed a simultaneous determination method of all polyphenols in vegetables, reported that the major polyphenols were caffeic acid (a simple polyphenol) and kaempferol glycoside in A. fistulosum and quercetin glycoside in A. cepa. Ren et al. (2001) found caffeic acid in the green leaf tissues of A. fistulosum. Caffeic acid and glycosides of kaempferol and quercetin are a phenylpropanoid and a flavonoid, respectively. The ubiquitous plant enzymes PAL (Langer et al., 1997) and chalcone synthase (CHS) (Ferrer et al., 1999) are key biosynthetic catalysts in phenylpropanoid and flavonoid assembly, respectively. In the present study, the PAL gene was allocated to chromosome 2A of shallot. Masuzaki et al. (2006a) revealed that the CHS-A gene was assigned to chromosome $2 \mathrm{~A}$ of shallot. The higher polyphenol accumulation observed in the green leaf tissue of $\mathrm{FF}+$ $2 \mathrm{~A}$ could have been due to the higher expression of these enzyme genes. Thus, anonymous genes by the gene dosage effect related to the upregulation of polyphenol production, other than PAL, could be located on chromosome 5A, 6A, and 8A.

Rice-Evans et al. (1995) noted that polyphenolic compounds were active mainly due to their redox properties, which allowed them to act as reducing agents, hydrogen donators, and reactive oxygen quenchers. Wang et al. (2005) reported that the polyphenol compounds in A.fistulosum were the main active compounds contributing to antioxidant activity. Further biochemical analyses and examinations of the chromosomal assignment of genes associated with polyphenol production are necessary to reveal the polyphenol production related to antioxidant activity in A. fistulosum and shallot.

\section{Literature Cited}

Bahorun, T., A. Luximon-Ramma, A. Crozier and O. Aruoma 2004. Total phenol, flavonoid, proanthocyanidin and vitamin $\mathrm{C}$ levels and antioxidant activities of Mauritian vegetables. J. Sci. Food Agric. 84: 1533-1561.

Bravo, L. 1998. Polyphenols: chemistry, dietary sources metabolism and nutritional significance. Nutr. Rev. 56: 317 333.

Chu, Y-H., C-L. Chang and H.-F. Hsu. 2000. Flavonoid content of several vegetables and their antioxidant activity. J. Sci. Food Agric. 80: 561-566.

Chu, Y-F., J. Sun, X. Wu and R. H. Liu. 2002. Antioxidant and antiproliferative activities of common vegetables. J. Agric. Food Chem. 50: 6910-6916.

Ferrer, J-L., J. M. Jez, M. E. Bowman, R. A. Dixon and J. P. Noel. 1999. Structure of chalcone synthase and the molecular basis of plant polyketide biosynthesis. Nature Struct. Biol. 6 : $775-784$.

Folin, O. and W. Denis. 1915. A colorimetric method for the determination of phenols (and phenol derivatives) in urine. J. Biol. Chem. 22: 305-308.

Hang, T. T. M., M. Shigyo, S. Yaguchi, N. Yamauchi and Y. Tashiro. 2004. Effect of single alien chromosome from shallot (Allium cepa L. Aggregatum group) on carbohydrate production in leaf blade of bunching onion (A. fistulosum L.). Genes Genet. Syst. 79: 345-350.

Langer, B., D. Röther and J. Rétey. 1997. Identification of essential amino acids in phenylalanine ammonia-lyase by site-directed mutagenesis. Biochemistry 36: 10867-10871.

Masuzaki, S., M. Shigyo and N. Yamauchi. 2006a. Complete assignment of structural genes involved in flavonoid biosynthesis influencing bulb color to individual chromosomes of shallot (Allium cepa L.). Genes Gent. Syst. 81: 255 262.

Masuzaki, S., M. Shigyo and N. Yamauchi. 2006b. Direct comparison between genomic constitution and flavonoid contents in Allium multiple alien addition lines reveals chromosomal locations of genes related to biosynthesis from dihydrokaempferol to quercetin glucosides in scaly leaf of shallot (Allium cepa L.). Theor. Appl. Genet. 112: 607-617.

Ren, H., H. Endo and T. Hayashi. 2001. Antioxidative and antimutagenic activities and polyphenol content of pesticidefree and organically cultivated green vegetables using watersoluble chitosan as a soil modifier and leaf surface spray. J. Sci. Food Agric. 81: 1426-1432.

Rice-Evans, C. A., N. J. Miller, P. G. Bolwell, P. M. Bramley and J. B. Pridham. 1995. The relative antioxidant activities of plantderived polyphenolic flavonoids. Free Radic. Res. 22: 375-383. 
Sakakibara, H., Y. Honda, S. Nakagawa, H. Ashida and K. Kanazawa. 2003. Simultaneous determination of all polyphenols in vegetables, fruit, and teas. J. Agric. Food. Chem. 51: 571-581.

Shigyo, M., M. Iino, S. Isshiki and Y. Tashiro. 1997a. Morphological characteristics of a series of alien monosomic addition lines of Japanese bunching onion (Allium fistulosum L.) with extra chromosomes from shallot (A. cepa L. Aggregatum group). Genes Genet. Syst. 72: 181-186.

Shigyo, M., Y. Tashiro, M. Iino, N. Terahara, K. Ishimaru and S. Isshiki. 1997b. Chromosomal locations of genes related to flavonoid and anthocyanin production in leaf sheath of shallot (Allium cepa L. Aggregatum group). Genes Genet. Syst. 72: 149-152.

Shigyo, M., Y. Tashiro, S. Isshiki and S. Miyazaki. 1996. Establishment of a series of alien monosomic addition lines of Japanese bunching onion (Allium fistulosum L.) with extra chromosomes from shallot (A. cepa L. Aggregatum group). Genes Genet. Syst. 71: 363-371.

Tomas-Barberan, F. A. and J. C. Espin. 2001. Phenolic compounds and related enzymes as determinants of quality in fruits and vegetables. J. Sci. Food Agric. 81: 853-879. van Heusden, A. W., J. W. van Ooijen, R. Vrielink-van Ginkel, W. H. J. Verbeek, W. A. Wietsma and C. Kik. 2000. A genetic map of an interspecific cross in Allium based on amplified fragment length polymorphism (AFLP $\left.{ }^{\mathrm{TM}}\right)$ markers. Theor. Appl. Genet. 100: 118-126.

Wang, B. S., J. H. Chen, Y. C. Liang and P. D. Duh. 2005. Effects of Welsh onion on oxidation of low-density lipoprotein and nitric oxide production in macrophage cell line RAW 264.7. Food Chem. 91: 147-155.

Yaguchi, S., M. Atarashi, M. Iwai, S. Masuzaki, N. Yamauchi and M. Shigyo. 2008a. Production of alien addition lines in polyploid bunching onion (Allium fistulosum) carrying 1A chromosome(s) of shallot (Allium cepa) and their application to breeding for a new vitamin $\mathrm{C}$-rich vegetable. J. Amer. Soc. Hort. Sci. 133: 367-373.

Yaguchi, S., J. McCallum, M. Shaw, M. Pither-Joyce, S. Onodera, N. Shiomi, N. Yamauchi and M. Shigyo. 2008b. Biochemical and genetic analysis of carbohydrate accumulation in Allium cepa L. Plant Cell Physiol. 49: 730-739.

Yang, J., K. J. Meyers, J. Van Der Heide and H. L. Rui. 2004. Varietal differences in phenolic content and antioxidant and antiproliferative activities of onions. J. Agric. Food Chem. 52: 6787-6793. 